\title{
Evaluation of Visceral Adiposity Index and Vitamin D Status in Colon Cancer: Is Visceral Obesity the Missing Link?
}

\author{
Mohamed M. Aboelnaga ${ }^{\mathrm{a}, \mathrm{e}}{ }^{\mathbb{B}}$, Engy M. Aboelnaga ${ }^{\mathrm{b}}$, Seham E.A. Abdelkhalek ${ }^{\mathrm{b}}$, \\ Mostafa El Shaerc ${ }^{c}$ Nahed Abdallah ${ }^{\mathrm{d}}$
}

\begin{abstract}
Background: We aimed to evaluate the effect of visceral obesity and vitamin D status on colon cancer and to investigate the possible link between visceral obesity and vitamin $\mathrm{D}$ in those patients.

Methods: This case-control study included 60 colon cancer patients and 40 subjects as control. Clinical, anthropometric, and pathological data were collected. Calculation of visceral adiposity index (VAI) and detection of vitamin D (25(OH)D) levels were performed and compared between groups.
\end{abstract}

Results: There were significant differences in VAI and level of $25(\mathrm{OH}) \mathrm{D}$ between both groups. Moreover, we found a significantly higher prevalence of vitamin D deficiency in the patient' group $(53.3 \%)$ versus the control group $(32.5 \%)$. There was a significant different mean of VAI in vitamin $\mathrm{D}$ deficient patients versus non-deficient patients $(\mathrm{P}=0.024)$. We found a significantly different means of VAI and vitamin D in the patients' group with different TNM stages, as higher stages are associated with a lower level of vitamin D and higher VAI.

Conclusions: VAI and 25(OH)D were different in colon cancer patients compared with control. Likewise, they had different means with different TNM stages. Vitamin D may augment the inflammatory status in visceral obesity which is involved in tumorigenesis of colon cancer.

Keywords: Colon cancer; 25-hydroxyvitamin D; Visceral adiposity index; Visceral obesity

Manuscript submitted July 19, 2021, accepted August 25, 2021

Published online October 31, 2021

aEndocrinology and Diabetes Unit, Faculty of Medicine, Mansoura University, Egypt

${ }^{\mathrm{b}}$ Clinical Oncology and Nuclear Medicine Department, Mansoura University Hospital, Mansoura, Egypt

'Department of Microbiology at Specialized Medical Hospital, Faculty of Medicine, Mansoura University, Egypt

dDepartment of Physiology at Specialized Medical Hospital, Faculty of Medicine, Mansoura University, Egypt

${ }^{\mathrm{e}}$ Corresponding Author: Mohamed M. Aboelnaga, Endocrinology and Diabetes Unit, Faculty of Medicine, Mansoura University, 2 El Gomhouria Street, Mansoura 35516, Egypt. Email: dr.mhd.endocrine@gmail.com

doi: https://doi.org/10.14740/jem762

\section{Introduction}

Colorectal cancer (CRC) is the third most common cancer worldwide and is one of the main causes of cancer-specific death [1]. A variety of risk factors have been recognized in pathogenesis of CRC, including low 25-hydroxyvitamin D (25(OH)D) [2]. Survival of CRC is positively associated with vitamin D status [3].

Many studies tried to postulate mechanisms for this apparent protective effect of $25(\mathrm{OH}) \mathrm{D}$, and tried to hypothesize mechanisms for this antineoplastic protective effect of vitamin D. These include impact of vitamin D on transcriptional regulation of anticancer genes which involved in cell proliferation, differentiation and apoptosis [4], and inflammatory markers $[5,6]$, but still without conclusive results.

On the other hand, Obesity is considered one of the most important metabolic disorders of this century with serious comorbidities, and has been linked to the most relevant cancers, like CRC [7]. However, adipose tissue distribution in the body is diverse. Visceral fat tissue appears to enhance adverse metabolic outcomes [8], and is thought to predispose to chronic inflammation and release of growth factors that thought to mediate colonic neoplasia [9].

In the same vein, Amato et al in 2010 individuated a novel easily applicable and sex-specific index for the evaluation of visceral adiposity dysfunction; visceral adiposity index (VAI) combined body mass index (BMI), waist circumference (WC), high-density lipoprotein cholesterol (HDL-C) and triglycerides [10]. VAI calculated from a combination of functional and anthropometric parameters may be a useful index for assessing visceral fat functional activity [11].

Relationship between circulating vitamin $\mathrm{D}$ levels and abdominal obesity was reported in many studies [12]. Therefore, this relationship could hypothesize the protective action of vitamin D in colorectal carcinoma and should be evaluated in CRC patients.

We aimed in our work to investigate effect of visceral obesity and vitamin $\mathrm{D}$ status on colon cancer among newly diagnosed colon cancer patients; also, to evaluate the possible link between visceral obesity and vitamin $\mathrm{D}$ in those patients.

\section{Patients and Methods}

The current study was conducted at the Clinical Oncology 
and Nuclear Medicine Department and Endocrinology Unit at Mansoura University Hospital, from July 2019 to June 2020. Our patients were distributed into two groups. The first group included colon cancer cases and the second group included control cases that participated in the study. We enrolled $60 \mathrm{pa}-$ tients with newly diagnosed colon cancer and 40 participants in the control group. Controls were matched according to age, gender, weight, waist, height, and BMI. All these subjects had a BMI $<40$ as we exclude obesity in order to ensure BMI homogeneity in both participants groups.

All the participants were informed about the nature of the study and provided their written consents. The study was approved by the Institutional Review Board of Faculty of Medicine, Mansoura University, and our Ethics and Research Committee in Mansoura University, Egypt; and was performed according to the Helsinki Declaration 1964.

Inclusion criteria were as follows: age above 18; sex; histopathological diagnosis of adenocarcinoma of colorectal carcinoma; all stages; and normal hepatic and kidney functions. Whereas exclusion criteria were: other pathological types; patients on vitamin D supplements; patients on medications that could affect vitamin D levels or disorders which could affect vitamin D levels such as malabsorption disorders; patients with autoimmune diseases; endocrinopathies associated with hypovitaminosis $\mathrm{D}$ level or obesity including diabetes mellitus also were excluded from this study; anti-obesity drugs use at the time of diagnosis or in previous 6 months; hepatic or renal failure.

The following data were recorded: clinical data including age and gender; anthropometric parameters including height, weight and WC; pathological data including stage of disease, nodal staging, pathological type, neurovascular invasion, and site of tumor. BMI was calculated according to the standard formula: $\mathrm{BMI}=$ weight in $\mathrm{kg}$ divided by square height in $\mathrm{m}$. $\mathrm{WC}$ was measured as the smallest circumference around the abdomen at the level of the umbilicus without any clothing.

VAI was calculated according to the formula, where triglyceride level and HDL-C were expressed in $\mathrm{mmol} / \mathrm{L}, \mathrm{WC}$ in $\mathrm{cm}$, and $\mathrm{BMI}$ in $\mathrm{kg} / \mathrm{m}^{2}$ [10].

$$
\begin{aligned}
& \text { VAI }=\frac{\text { Waist }}{36.68+(1.88 \times \mathrm{BMI})} \times \frac{\text { Triglyceride }}{1.03} \times \frac{1.31}{\mathrm{HDL}-\mathrm{C}} \text { for male } \\
& \mathrm{VAI}=\frac{\text { Waist }}{36.58+(1.89 \times \mathrm{BMI})} \times \frac{\text { Triglyceride }}{0.81} \times \frac{1.52}{\mathrm{HDL}-\mathrm{C}} \text { for female }
\end{aligned}
$$

Morning venous blood samples were drawn after a 10 - 12 $\mathrm{h}$ overnight fast. The serum was separated by centrifugation immediately frozen at $-80{ }^{\circ} \mathrm{C}$ until analysis. Serum glucose, cholesterol, triglycerides, HDL-C, and C-reactive protein (CRP) were measured. Low-density lipoprotein cholesterol (LDL-C) was calculated using the Friedewald equation. Vitamin D $(25(\mathrm{OH}) \mathrm{D})$ serum level was detected using enzymelinked immunosorbent assay (ELISA). 25(OH) vitamin D levels below $30 \mathrm{ng} / \mathrm{mL}$ are considered as insufficiency while values lower than $20 \mathrm{ng} / \mathrm{mL}$ as deficiency.

\section{Data analysis}

The SPSS statistical version 23.0 was used for data analysis; the results were given as the mean \pm standard deviation for continuous variables and as a percentage for categorical data. We used an independent $t$-test for the comparison of continuous variables between patients and control groups. While for categorical data, the Chi-square test was used. We used multivariate analysis for confirmation of significant results in the independent $t$-test after adjustment of the confounding factors. The analysis of variance (ANOVA) for independent samples was used to compare the differences in means between the different patients' grades. $\mathrm{P}$ value less than 0.05 was considered to be statistically significant for all tests.

\section{Results}

Sixty patients with newly diagnosed colon cancer were enrolled in this case-control study. Patients' ages ranged from 39 to 65 years (mean age $56.97 \pm 5.58$ years). Forty participants were matched according to age, height, weight, waist, and BMI as the control group. The control group was compared to the patients' group. Despite the nonsignificant difference in weight, height, waist, and BMI between patients and control groups, there were significant differences in VAI, HDL and triglyceride levels. Furthermore, the level of $25(\mathrm{OH})$ vitamin $\mathrm{D}$ was significantly lower in the patients' group $(\mathrm{P}=0.011)$. In addition, we found a significantly higher prevalence of vitamin D deficiency in the patient group $32(53.3 \%)$ of patients than in the control group $13(32.5 \%, \mathrm{P}=0.032)$. Other details of both groups' characteristics were presented in Table 1.

We used multivariate analysis to evaluate the effect of confounder variables like age, BMI, and sex on the significant variable in the comparison between patients and control groups. We observed that HDL-C, triglyceride, VAI, and $25(\mathrm{OH})$ vitamin D were still significant after adjustment for confounding factors. We adjusted for age, BMI, and sex separately and adjustment of all factors together. Other data were detailed in Table 2.

In the patients' group, we compared clinical, anthropometric, and laboratory parameters in 28 patients with vitamin D deficiency versus 32 non-deficient patients. There was a statistically significantly lower mean of VAI in vitamin D deficient patients versus non-deficient cases $(P=0.024)$. However, insignificant differences in other parameters were found. Other details were shown in Table 3.

Tumor characteristics of the 60 colon cancer patients were posted in Table 4.

In this study, we found a statistically significant different means of VAI and vitamin D in patients with different TNM stages, as higher stages are associated with lower-level vita$\min \mathrm{D}(\mathrm{P}=0.027)$ and higher VAI $(\mathrm{P}=0.031)$. No significant differences in means of VAI and vitamin $\mathrm{D}$ were found when comparing the pathological type, nodal staging, tumor location, and neurovascular invasion in the patients' group. Other data were detailed in Table 5.

\section{Discussion}

Despite extensive research evaluated the relation of obesity 
Table 1. Baseline Characteristics of Study Groups

\begin{tabular}{|c|c|c|c|}
\hline Variables & Patients group $(n=60)$ & Control group $(n=40)$ & Corrected P value \\
\hline Age (years) & $56.97 \pm 5.58$ & $56.78 \pm 7.22$ & 0.882 \\
\hline \multicolumn{4}{|l|}{ Gender, n (\%) } \\
\hline Female & $18(30 \%)$ & $14(35 \%)$ & \\
\hline Height (m) & $1.69 \pm 0.078$ & $1.69 \pm 0.0795$ & 0.645 \\
\hline Waist (cm) & $112.42 \pm 18.22$ & $109.83 \pm 16.0$ & 0.467 \\
\hline $\mathrm{FBS}(\mathrm{mg} / \mathrm{dL})$ & $100.9 \pm 9.78$ & $98.5 \pm 8.57$ & 0.207 \\
\hline Total cholesterol (mg/dL) & $241.97 \pm 54.19$ & $226.65 \pm 38.34$ & 0.125 \\
\hline LDL-C (mg/L) & $148.95 \pm 73.16$ & $136.32 \pm 59.51$ & 0.188 \\
\hline $25(\mathrm{OH})$ vitamin $\mathrm{D}$ & $19.39 \pm 9.297$ & $24.1 \pm 8.425$ & 0.011 \\
\hline Vitamin D deficiency & $32(53.3 \%)$ & $13(32.5 \%)$ & 0.032 \\
\hline
\end{tabular}

All values were provided as mean \pm standard deviation (SD) or ratio. BMI: body mass index; FBS: fasting blood sugar; LDL-C: low-density lipoprotein cholesterol; HDL-C: high-density lipoprotein cholesterol; VAl: visceral adiposity index.

Table 2. Significant Variables After Adjustment for Other Factors

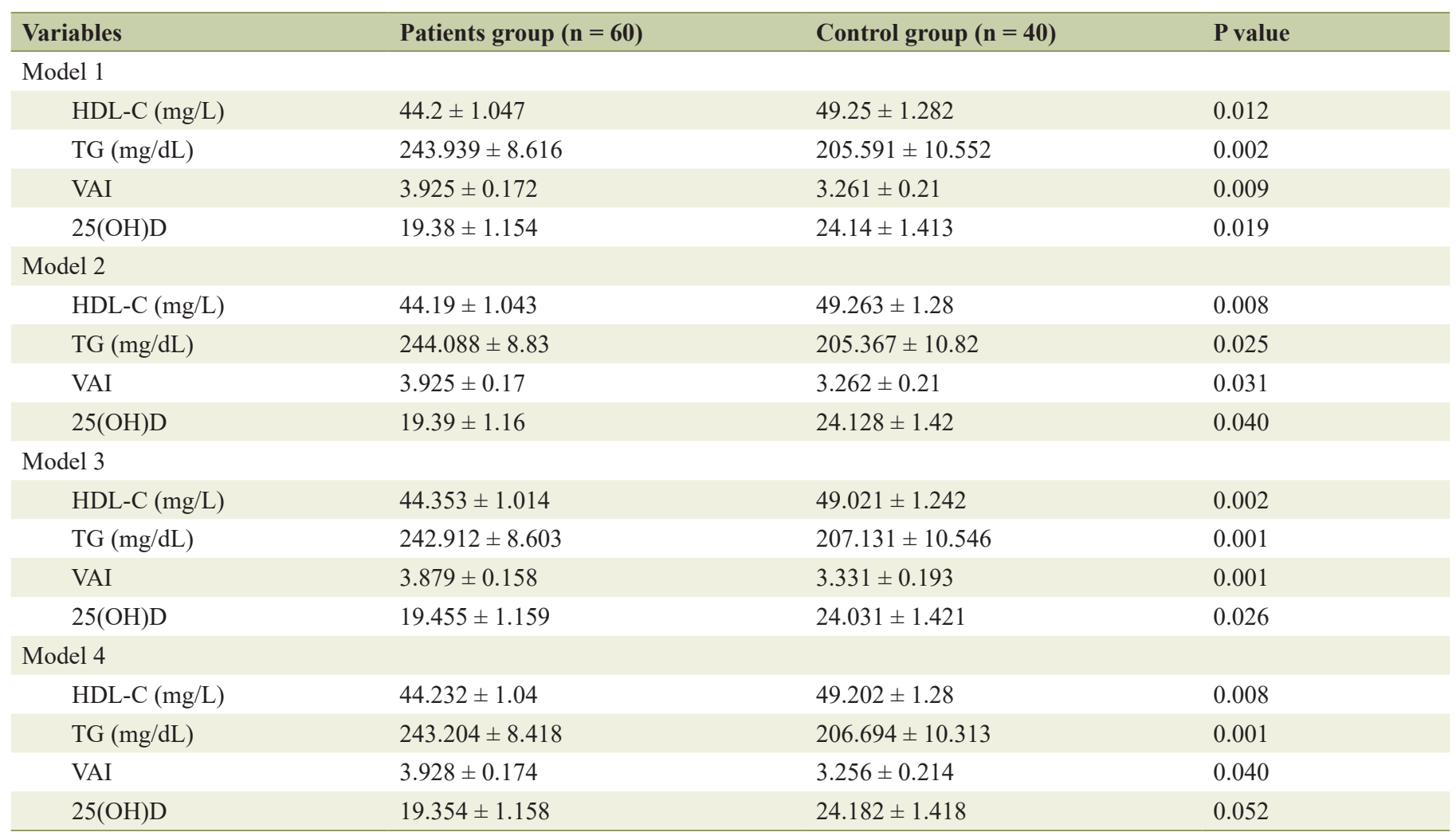

All values were provided as mean \pm standard error. Model 1: adjusted for age, BMI, and sex. Model 2: adjusted for age. Model 3: adjusted for BMI. Model 4: adjusted for sex. HDL-C: high-density lipoprotein cholesterol; TG: triglyceride; VAl: visceral adiposity index; 25(OH)D: 25-OH vitamin D; BMI: body mass index. 
Table 3. Comparison Between Non-Deficient Vitamin D Levels Versus Deficient Vitamin D Patients in Colon Cancer Group

\begin{tabular}{|c|c|c|c|}
\hline Variables & $\begin{array}{l}\text { Non-deficient vitamin D }(25 \\
(O H) D>20.00)(n=32)\end{array}$ & $\begin{array}{l}\text { Deficient vitamin } D(25 \\
(O H) D<20.00)(n=28)\end{array}$ & P value \\
\hline Age (years) & $57.93 \pm 4.37$ & $56.13 \pm 6.41$ & 0.215 \\
\hline \multicolumn{4}{|l|}{ Gender } \\
\hline Male & $22(68.8 \%)$ & $20(71.4 \%)$ & 0.5 \\
\hline Female & $10(31.2 \%)$ & $8(28.6 \%)$ & \\
\hline BMI $\left(\mathrm{kg} / \mathrm{m}^{2}\right)$ & $32.12 \pm 4.869$ & $32.18 \pm 5.32$ & 0.968 \\
\hline Weight (kg) & $90.89 \pm 15.53$ & $92.03 \pm 18.25$ & 0.797 \\
\hline Waist $(\mathrm{cm})$ & $109.71 \pm 15.9$ & $114.78 \pm 19.96$ & 0.286 \\
\hline Total cholesterol (mg/L) & $242.82 \pm 52.6$ & $241.22 \pm 56.36$ & 0.91 \\
\hline LDL-C (mg/L) & $150.64 \pm 48.27$ & $147.47 \pm 54.18$ & 0.813 \\
\hline FBS (mg/dL) & $101.79 \pm 9.82$ & $100.156 \pm 9.85$ & 0.525 \\
\hline
\end{tabular}

All values were provided as mean \pm standard deviation (SD) or ratio. $25(\mathrm{OH}) \mathrm{D}$ : $25-\mathrm{OH}$ vitamin D; BMI: body mass index; HDL-C: high-density lipoprotein cholesterol; LDL: low-density lipoprotein cholesterol; VAI: visceral adiposity index; FBS: fasting blood sugar.

Table 4. Tumor Characteristics in Patients' Group $(\mathrm{N}=60)$

\begin{tabular}{|c|c|}
\hline Variables & N (\%) \\
\hline \multicolumn{2}{|l|}{ TNM stage } \\
\hline I & $10(16.7 \%)$ \\
\hline II & $13(21.7 \%)$ \\
\hline III & $23(38.3 \%)$ \\
\hline IV & $14(23.3 \%)$ \\
\hline \multicolumn{2}{|l|}{ Nodal staging } \\
\hline N0 & $19(31.65 \%)$ \\
\hline N1 & $22(36.7 \%)$ \\
\hline $\mathrm{N} 2$ & $19(31.65 \%)$ \\
\hline \multicolumn{2}{|l|}{ Pathology type } \\
\hline Adenocarcinoma & $41(68.3 \%)$ \\
\hline Mucoid type & $12(20 \%)$ \\
\hline Signet ring type & $7(11.7 \%)$ \\
\hline \multicolumn{2}{|l|}{ LVI/PNI } \\
\hline Negative & $14(61.7 \%)$ \\
\hline Positive & $37(23.3 \%)$ \\
\hline Unknown & $9(15 \%)$ \\
\hline \multicolumn{2}{|l|}{ Site of tumor } \\
\hline Right & $23(38.3 \%)$ \\
\hline Left & $22(36.7 \%)$ \\
\hline Transverse & $11(6.7 \%)$ \\
\hline Sigmoid & $4(18.3 \%)$ \\
\hline
\end{tabular}

LVI: lymphovascular invasion; PNI: perineural invasion. with colon cancer, the relationship of obesity with colon cancer is still inconsistent. In this study, we highlighted the potential role of visceral fat functional activity in colon cancer. Furthermore, we evaluated the link between visceral obesity activity and vitamin D status in colon cancer patients.

The main result in this study was that patients with colon cancer associated with a higher functional activity of visceral obesity and lower 25(OH) vitamin D levels, in comparison with age, height, weight, waist, and BMI matched control subjects. Moreover, we found that the activity of visceral fat correlates with the staging of colon cancer patients. These results augment the hypothesis of the role of proinflammatory status associated with visceral obesity in the development of colon carcinoma. In addition, the hypovitaminosis D associated with the higher visceral fat functional activity may hypothesize for a speculated mechanism for tumorigenesis in carcinoma of the colon via visceral obesity.

In our study, we found that colon cancer patients had a higher VAI index denoting higher functional activity of adipose tissue in comparison with matched subjects. Moreover, the advanced stage of colon cancer had higher VAI. These results concluded that the activity of adipose tissue was more linked with cancer than obesity itself defined by BMI or visceral obesity defined by the WC.

Many studies evaluated the relationship between obesity and CRC. Nevertheless, the findings have been inconsistent regarding this relationship [13]. Mounting evidence indicates that obesity may be associated with the risk of colon cancer by a large number of studies and review papers [2, 14-17]. However, other studies suggested that obesity was a greater risk for colon cancer in males but not females, thus providing inconclusive results regarding their relationship and gender effect [18]. Therefore, the magnitude of the association has varied 
Table 5. Comparison of Tumor Characteristics in Relation to 25-OH Vitamin D Level, BMI and VAI

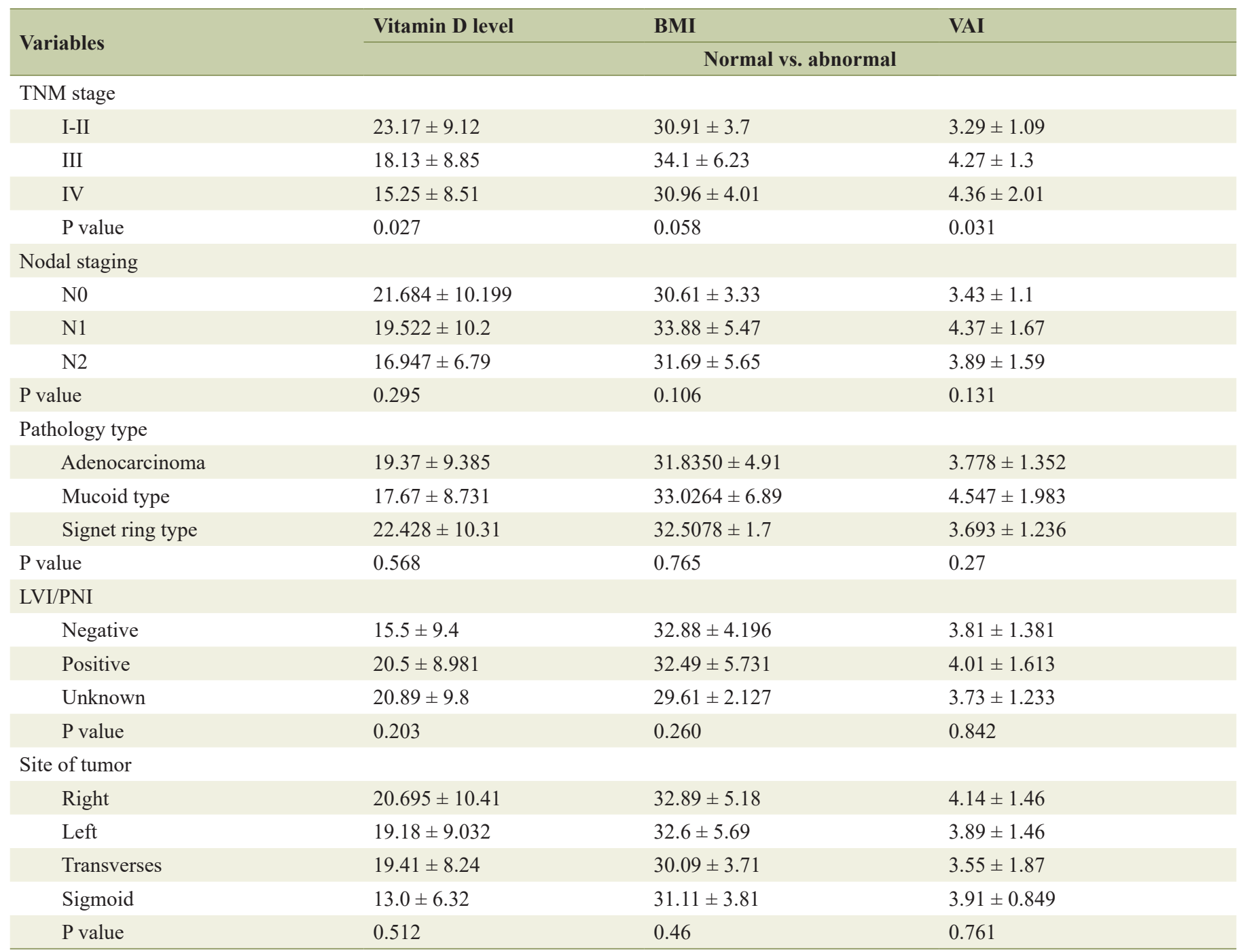

BMI: body mass index; VAl: visceral adiposity index; LVI: Iymphovascular invasion; PNI: perineural invasion.

widely across studies. In addition, no overall quantitative estimate has previously been reported due to different sociodemographic characteristics of participants and methodologies used to assess obesity in each study. In contrast to the consistent and strong evidence linking obesity with carcinoma of the colon, few studies did not find an association between obesity and CRC [14, 19].

The mechanisms that link excess body fat and carcinogenesis are not fully elucidated. However, few mechanisms have been postulated to explain the obesity correlation with colon neoplasia. First, the mechanism that obesity leads to resistance insulin and hyperinsulinemia was proposed, which consequently reduces insulin-like growth factor binding protein (IGFBP-1) levels while elevating levels of insulin-like growth factor-1(IGF-1) [20]. IGF-1 is responsible for cancer-promoting effects, favoring tumor growth, increases cell proliferation and inhibits apoptosis, increasing cell migration, and ultimately may lead to metastasis $[21,22]$. The second mechanism, a variety of adipokines secreted by adipose tissue have potent proinflammatory cytokines, such as interleukin (IL)-6 and tumor necrosis factor (TNF)- $\alpha$, these cytokine hypersecretions result in a state of chronic inflammation which could promote tumor initiation and progression by acting as mitogens for normal and neoplastic colon cells [23, 24]. Thirdly, as hormonally active tissue, obesity alters adipose tissue-derived adipokines levels, such as adiponectin, leptin, and resistin [25]. Leptin has tumorigenic bioactivity, acts as a potent mitogen, and regulates angiogenesis or apoptosis through several signaling pathways [26]. Adiponectin could reduce cell proliferation rate and induce cells apoptosis as demonstrated in many studies [27]. In the same vein, it was reported recently that higher plasma levels of resistin in connection with insulin resistance play a role in susceptibility to colorectal carcinoma [28].

Adipose tissue is very heterogeneous and current evidence could suggest that visceral adipose tissue (VAT) is associated with more obesity-related comorbidity and mortality than sub- 
cutaneous fat tissue [20]. This could partially be explained by the unique architecture of VAT. The visceral is a highly vascular, cellular organ, and contains cells with inflammatory and immunological functions. In addition, the close proximity of visceral fat to the portal vein causes excess free fatty acids drainage and inflammatory cytokines directly to the liver, therefore could affect metabolism [7]. Sex-based differences in VAT may relate to different sex hormones profile [29].

The characteristic in our studies is the comparison of functional activity of VAT in colon cancer patients with anthropometric parameters-matched control subjects, and the use of VAI by the combination of both anthropometric and functional parameters. Moreover, VAI has a different formula for both genders. With consideration of gender effect on visceral obesity, VAI may be more predictive in the evaluation of central obesity risks than anthropometric parameters alone. In addition, we reported that vitamin $\mathrm{D}$ levels tend to be lower in the patients' group. Also, vitamin D deficient patients had higher VAI than non-deficient patients despite the nonsignificant difference in BMI and waist.

A protective effect of vitamin $\mathrm{D}$ in $\mathrm{CRC}$ has been reported more than three decades ago, many extensive studies and meta-analyses linked vitamin D level with the incidence of CRC and survival [30-33]. In the same vein, an inverse association between vitamin D intake and CRC incidence was reported [34]. Our results were in concordance with previous studies' results. On the other hand, few exceptional studies reported the absence of this association $[35,36]$. Furthermore, a 7 -year study reported no effect of vitamin D supplementations for 7 years on the incidence of CRC [37].

In recent years, attention has been focused on pleiotropic directions of effects exerted by vitamin D [38]. Evidence from many in vitro and in vivo researches reported that active vitamin D had immune modulation, antiangiogenesis, antiproliferation, pro-differentiation, and pro-apoptosis effects. Moreover, vitamin D regulates the release of cytokines, such as IL-6, IL8 , and microRNA regulation which participate in the antitumor effect of vitamin D [39]. Many studies have reported a consistent link of circulating vitamin D concentration with CRC incidence and mortality; however, this strong correlation between vitamin $\mathrm{D}$ and colon cancer mostly weakened after adjustment for obesity parameters [40].

Vitamin D deficiency is associated with various chronic diseases including adiposity and metabolic disorders such as insulin resistance. An association between hypovitaminosis $\mathrm{D}$ and obesity has consistently been demonstrated in many studies [41]. However, the nature of this association between hypovitaminosis D and obesity remains poorly understood [41]. Some studies speculated that active vitamin D might block the expression of fatty acid synthase enzyme in adipocytes, hence, inhibit adipogenesis [42]. While others thought this inverse relationship is a result of enhanced metabolic clearance in adipose tissue [43]. Another study suggested the decreased bioavailability of cutaneous synthesis of vitamin D3 in obese individuals [44]. Recently, there is an ongoing discussion about that low vitamin D status may simply indicate poor health status rather than a causal factor itself [45].

In the light of our study results, we hypothesized that vitamin D may augment the inflammatory status in visceral obe- sity, which is reported to be involved in tumorigenesis of colon cancer. Vitamin D may be a mediator between obesity and cancer. We suggest that functional activity rather than obesity is involved in the pathogenesis of this tumor.

The previous result suggested that vitamin D may augment the inflammatory status in visceral obesity which is reported to be involved in colonic tumorigenesis; and functional activity rather than obesity is involved in tumor pathogenesis.

Our study has some limitations that also warrant mentioning. Firstly, this study had a case-control design; we could not evaluate the duration of visceral obesity and could not evaluate recent changes. Secondly, we did not evaluate calcitriol (1 $\alpha, 25$-dihydroxy vitamin $\left.\mathrm{D}_{3}\left(1,25(\mathrm{OH})_{2} \mathrm{D}_{3}\right)\right)$, the most active form of vitamin $\mathrm{D}$, responsible for most of its biological actions due to financial issues. Thirdly, radiological investigation was not used for precise quantification of adiposity volume. However, we used waist measurement to estimate visceral fat; and WC provides a simple yet effective measure of visceral fat [36]. Fourth limitation is exclusion of patients with BMI more than 40 to avoid abnormality of distribution of study data. Finally, a relatively small number of patients were recruited in our study. Larger studies will be needed for confirmation of our results.

\section{Conclusions}

We could conclude from this study that both visceral obesity and vitamin $\mathrm{D}$ deficiency are associated with higher risk of colon cancer, but the extent of this association still need more exploration. Vitamin D deficiency might augment the proinflammatory state in visceral obesity and this could be a link between vitamin $\mathrm{D}$ and visceral obesity in colon cancer pathogenesis. Moreover, higher VAI and vitamin D deficiency are associated with higher tumor stage in colon cancer.

\section{Acknowledgments}

This work was supported by the Specialized Medical Hospital staff at Mansoura University.

\section{Financial Disclosure}

None to declare.

\section{Conflict of Interest}

None to declare.

\section{Informed Consent}

All the participants were informed about the nature of the study and provided their written consents. 


\section{Authors Contributions}

MA, EA, and SA contributed to the conception and interpretation of the data, and were involved in writing, reviewing, and editing the manuscript. NA and MES performed the laboratory tests. MA performed the statistical analysis, writing original draft, review and editing. All authors read and approved the final manuscript.

\section{Data Availability}

The data supporting the findings of this study are available from the corresponding author upon reasonable request.

\section{References}

1. Torre LA, Bray F, Siegel RL, Ferlay J, Lortet-Tieulent J, Jemal A. Global cancer statistics, 2012. CA Cancer J Clin. 2015;65(2):87-108.

2. Haggar FA, Boushey RP. Colorectal cancer epidemiology: incidence, mortality, survival, and risk factors. Clin Colon Rectal Surg. 2009;22(4):191-197.

3. van Harten-Gerritsen AS, Balvers MG, Witkamp RF, Kampman E, van Duijnhoven FJ. Vitamin D, inflammation, and colorectal cancer progression: a review of mechanistic studies and future directions for epidemiological studies. Cancer Epidemiol Biomarkers Prev. 2015;24(12):18201828.

4. Feldman D, Krishnan AV, Swami S, Giovannucci E, Feldman BJ. The role of vitamin D in reducing cancer risk and progression. Nat Rev Cancer. 2014;14(5):342-357.

5. Ning Y, Manegold PC, Hong YK, Zhang W, Pohl A, Lurje G, Winder T, et al. Interleukin-8 is associated with proliferation, migration, angiogenesis and chemosensitivity in vitro and in vivo in colon cancer cell line models. Int J Cancer. 2011;128(9):2038-2049.

6. Klampfer L. Cytokines, inflammation and colon cancer. Curr Cancer Drug Targets. 2011;11(4):451-464.

7. Castellano-Castillo D, Morcillo S, Crujeiras AB, SanchezAlcoholado L, Clemente-Postigo M, Torres E, Tinahones FJ, et al. Association between serum 25-hydroxyvitamin D and global DNA methylation in visceral adipose tissue from colorectal cancer patients. BMC Cancer. 2019;19(1):93.

8. Del Corno M, D'Archivio M, Conti L, Scazzocchio B, Vari R, Donninelli G, Varano B, et al. Visceral fat adipocytes from obese and colorectal cancer subjects exhibit distinct secretory and omega6 polyunsaturated fatty acid profiles and deliver immunosuppressive signals to innate immunity cells. Oncotarget. 2016;7(39):63093-63105.

9. Perez-Hernandez AI, Catalan V, Gomez-Ambrosi J, Rodriguez A, Fruhbeck G. Mechanisms linking excess adiposity and carcinogenesis promotion. Front Endocrinol (Lausanne). 2014;5:65.

10. Amato MC, Giordano C, Galia M, Criscimanna A, Vitabile S, Midiri M, Galluzzo A, et al. Visceral Adiposity Index: a reliable indicator of visceral fat function associated with cardiometabolic risk. Diabetes Care. 2010;33(4):920-922.

11. Aboelnaga MM, Eladawy EH, Elshafei MM, Abdullah N, Shaer ME. Different cabergoline effect on metabolic and anthropometric parameters in female prolactinoma patients versus idiopathic hyperprolactinemia patients. Endocr Metab Immune Disord Drug Targets. 2019;19(4):511-518.

12. Zhang Y, Zhang X, Wang F, Zhang W, Wang C, Yu C, Zhao $\mathrm{J}$, et al. The relationship between obesity indices and serum vitamin $\mathrm{D}$ levels in Chinese adults from urban settings. Asia Pac J Clin Nutr. 2016;25(2):333-339.

13. Ma Y, Yang Y, Wang F, Zhang P, Shi C, Zou Y, Qin H. Obesity and risk of colorectal cancer: a systematic review of prospective studies. PLoS One. 2013;8(1):e53916.

14. Choe EK, Kim D, Kim HJ, Park KJ. Association of visceral obesity and early colorectal neoplasia. World J Gastroenterol. 2013;19(45):8349-8356.

15. Dong Y, Zhou J, Zhu Y, Luo L, He T, Hu H, Liu H, et al. Abdominal obesity and colorectal cancer risk: systematic review and meta-analysis of prospective studies. Biosci Rep. 2017;37(6):BSR20170945.

16. Odegaard AO, Koh WP, Yu MC, Yuan JM. Body mass index and risk of colorectal cancer in Chinese Singaporeans: the Singapore Chinese Health Study. Cancer. 2011;117(16):3841-3849.

17. Nagata N, Sakamoto K, Arai T, Niikura R, Shimbo T, Shinozaki M, Aoki T, et al. Visceral abdominal fat measured by computed tomography is associated with an increased risk of colorectal adenoma. Int J Cancer. 2014;135(10):22732281.

18. Ahmed RL, Schmitz KH, Anderson KE, Rosamond WD, Folsom AR. The metabolic syndrome and risk of incident colorectal cancer. Cancer. 2006;107(1):28-36.

19. Erarslan E, Turkay C, Koktener A, Koca C, Uz B, Bavbek N. Association of visceral fat accumulation and adiponectin levels with colorectal neoplasia. Dig Dis Sci. 2009;54(4):862-868.

20. Harvey AE, Lashinger LM, Hursting SD. The growing challenge of obesity and cancer: an inflammatory issue. Ann N Y Acad Sci. 2011;1229:45-52.

21. Giovannucci E. Metabolic syndrome, hyperinsulinemia, and colon cancer: a review. Am J Clin Nutr. 2007;86(3):s836-842.

22. Otani T, Iwasaki M, Sasazuki S, Inoue M, Tsugane S, Japan Public Health Center-based Prospective Study G. Plasma C-peptide, insulin-like growth factor-I, insulin-like growth factor binding proteins and risk of colorectal cancer in a nested case-control study: the Japan public health centerbased prospective study. Int J Cancer. 2007;120(9):20072012.

23. Grivennikov SI, Karin M. Inflammatory cytokines in cancer: tumour necrosis factor and interleukin 6 take the stage. Ann Rheum Dis. 2011;(Suppl 1):i104-108.

24. Rizzo A, Pallone F, Monteleone G, Fantini MC. Intestinal inflammation and colorectal cancer: a double-edged sword? World J Gastroenterol. 2011;17(26):3092-3100.

25. Joshi RK, Kim WJ, Lee SA. Association between obesity-related adipokines and colorectal cancer: a casecontrol study and meta-analysis. World J Gastroenterol. 2014;20(24):7941-7949. 
26. Riondino S, Roselli M, Palmirotta R, Della-Morte D, Ferroni P, Guadagni F. Obesity and colorectal cancer: role of adipokines in tumor initiation and progression. World J Gastroenterol. 2014;20(18):5177-5190.

27. Di Zazzo E, Polito R, Bartollino S, et al. Adiponectin as link factor between adipose tissue and cancer. Int J Mol Sci. 2019;20(4):839.

28. Farahani H, Mahmoudi T, Asadi A, Nobakht H, Dabiri R, Hamta A. Insulin resistance and colorectal cancer risk: the role of elevated plasma resistin levels. J Gastrointest Cancer. 2020;51(2):478-483.

29. Neeland IJ, Poirier P, Despres JP. Cardiovascular and metabolic heterogeneity of obesity: clinical challenges and implications for management. Circulation. 2018;137(13):13911406.

30. Garland CF, Comstock GW, Garland FC, Helsing KJ, Shaw EK, Gorham ED. Serum 25-hydroxyvitamin D and colon cancer: eight-year prospective study. Lancet. 1989;2(8673):1176-1178.

31. Song M, Nishihara R, Wang M, Chan AT, Qian ZR, Inamura K, Zhang X, et al. Plasma 25-hydroxyvitamin D and colorectal cancer risk according to tumour immunity status. Gut. 2016;65(2):296-304.

32. Weinstein SJ, Purdue MP, Smith-Warner SA, Mondul AM, Black A, Ahn J, Huang WY, et al. Serum 25-hydroxyvitamin $\mathrm{D}$, vitamin $\mathrm{D}$ binding protein and risk of colorectal cancer in the prostate, lung, colorectal and ovarian cancer screening trial. Int J Cancer. 2015;136(6):E654-664.

33. Zgaga L, Theodoratou E, Farrington SM, Din FV, Ooi LY, Glodzik D, Johnston S, et al. Plasma vitamin D concentration influences survival outcome after a diagnosis of colorectal cancer. J Clin Oncol. 2014;32(23):2430-2439.

34. Ma Y, Zhang P, Wang F, Yang J, Liu Z, Qin H. Association between vitamin $\mathrm{D}$ and risk of colorectal cancer: a systematic review of prospective studies. J Clin Oncol. 2011;29(28):3775-3782.

35. Weinstein SJ, Yu K, Horst RL, Ashby J, Virtamo J, Albanes D. Serum 25-hydroxyvitamin D and risks of colon and rectal cancer in Finnish men. Am J Epidemiol. 2011;173(5):499-508.

36. Anic GM, Weinstein SJ, Mondul AM, Mannisto S, Albanes
D. Serum vitamin D, vitamin D binding protein, and risk of colorectal cancer. PLoS One. 2014;9(7):e102966.

37. Wactawski-Wende J, Kotchen JM, Anderson GL, Assaf AR, Brunner RL, O'Sullivan MJ, Margolis KL, et al. Calcium plus vitamin D supplementation and the risk of colorectal cancer. N Engl J Med. 2006;354(7):684-696.

38. Aboelnaga MM, Abdullah N, El Shaer M. 25-hydroxyvitamin D correlation with prolactin levels and adenoma size in female patients with newly diagnosed prolactin secreting adenoma. Endocr Metab Immune Disord Drug Targets. 2017;17(3):219-225.

39. Dou R, Ng K, Giovannucci EL, Manson JE, Qian ZR, Ogino S. Vitamin D and colorectal cancer: molecular, epidemiological and clinical evidence. Br J Nutr. 2016;115(9):16431660 .

40. Shanmugalingam T, Crawley D, Bosco C, Melvin J, Rohrmann S, Chowdhury S, Holmberg L, et al. Obesity and cancer: the role of vitamin D. BMC Cancer. 2014;14:712.

41. Ruiz-Ojeda FJ, Anguita-Ruiz A, Leis R, Aguilera CM. Genetic factors and molecular mechanisms of vitamin D and obesity relationship. Ann Nutr Metab. 2018;73(2):8999.

42. Kong J, Li YC. Molecular mechanism of 1,25-dihydroxyvitamin D3 inhibition of adipogenesis in 3T3-L1 cells. Am J Physiol Endocrinol Metab. 2006;290(5):E916-924.

43. Blum M, Dolnikowski G, Seyoum E, Harris SS, Booth SL, Peterson J, Saltzman E, et al. Vitamin D(3) in fat tissue. Endocrine. 2008;33(1):90-94.

44. Wortsman J, Matsuoka LY, Chen TC, Lu Z, Holick MF. Decreased bioavailability of vitamin D in obesity. Am J Clin Nutr. 2000;72(3):690-693.

45. Schottker B, Saum KU, Perna L, Ordonez-Mena JM, Holleczek B, Brenner H. Is vitamin D deficiency a cause of increased morbidity and mortality at older age or simply an indicator of poor health? Eur J Epidemiol. 2014;29(3):199210.

46. Taylor RW, Jones IE, Williams SM, Goulding A. Evaluation of waist circumference, waist-to-hip ratio, and the conicity index as screening tools for high trunk fat mass, as measured by dual-energy X-ray absorptiometry, in children aged 3-19 y. Am J Clin Nutr. 2000;72(2):490-495. 